\title{
INTEGRATING FLOW SIMULATION FOR INJECTION MOULDING COMPONENT BASETTA TU BASE
}

\author{
Manjunatha. $\mathbf{M}^{1}$, Ramesh Babu.K ${ }^{2}$ \\ ${ }^{1}$ Department of PG studies, Govt. Tool Room and Training centre, Mysore -570016, Karnataka, India \\ ${ }^{2}$ Department of PG studies, Govt. Tool Room and Training centre, Mysore -570016, Karnataka, India
}

\begin{abstract}
Injection moulding is one of the manufacturing techniques to produce mass production of engineering components made of typical polymer materials. The mould and part design of plastic parts for injection moulding is a complicated process, considerations for producing a part ranging from cost and speed of production to structural, ergonomics and aesthetic requirements. One of the routines problem faced by a designer while designing the tool for good quality parts is the process of cavity balancing. This entails controlling the plastic flow in the filling phase such that the melt front reaches the boundaries of the mould at the same time. The Plastic flow analysis is done using Mould Flow analysis software. It is necessary to provide a flow-way in injection moulding to connect the nozzle to the each impression; this flow-way is termed as feed system, normally feed system consisting of sprue, runner and gate. Gate location can have a drastic effect on a part that could result in incorrect parts. The analysis was carried out to study the location of gate which reduces filling time and flow visualization improves the part quality considering bezel part as an example, this case study is done by mouldflow analysis tool, to ensure the concepts mentioned above.
\end{abstract}

Keywords: injection moulding, mould flow analysis, cavity, gate location, fill time.

\section{INTRODUCTION}

In the injection moulding process the injected polymer flows through the sprue, runners and gate to the cavity (or cavities). The polymer flow in mould channels is unsteady and non isothermal and depends on many factors, like the properties of polymer used, injection mould design (especially cavity shape and runner configuration), injection moulding machine and processing conditions. The polymer and the machine are usually the factors determined by moulded parts' manufacturers and consumers. The melt flow in mould runners can be controlled by the design and manufacturing technology of the mould as well as by the processing conditions in order to obtain the moulded parts with expected morphology, properties, shape, dimensions and surface. The cavity in the injection mould should be filled totally during the injection phase and the way of filling should be laminar and with a wide flow front - the stream flow (jetting phenomenon) should be avoided. In the case of multi cavity moulds simultaneous filling of all cavities is required in order to obtain the repeatable parts of a good quality, at low decrease in melt pressure and temperature. These requirements can be fulfilled when the proper melt flow in runners and gates is assured by the runners' and gates' design and proper processing conditions.

The way and sequence of filling of particular areas of mould cavity is the important issue. The decrease in melt temperature and pressure during the cavity filling should be as small as possible. The best situation would be if all border walls were reached by melt at the same time what is very difficult or even impossible to achieve in practice. The even cavity filling depends on the design of runner system (the number of injection points and their locations, the shape and dimensions of runners and gates), the accuracy of runner system manufacturing and the shape and dimensions of injection moulded parts (including the wall thickness and its distribution in the part). Sometimes it is necessary to control the melt flow in the cavity, for example in case of weld lines creation in the part. Weld lines should not be located in part's areas which are under load or, because of aesthetic reasons, in places which are visible during their using.

The use of plastics has become increasingly important as weight; cost and quality are standard points to stay competitive in the industry, plastics can be moulded into extremely complex shapes, good dimensional accuracy. The injection moulding operations can also sometimes be quite a challenge to the mould designer as to design a mould that produce products with fewer defects as weld lines and air traps. Currently, the process of trial and errors required at the tryout stage can be reduce through the Computer aided engineering (CAE) by simulation resin flow pattern and plastics material are easily tend to have warpage, shrinkage, and predicting possible defects that can be avoided by improving flow balance with the proper selection on gate location. 


\section{EXPERIMENT ANALYSIS.}

Analysis of the part is carried out using a mould flow software to determine how part fills and to foresee the potential defects such as sink marks, air entrapment areas, weld locations, etc. The part comprises of many ribs and bosses with varying wall thickness which eventually leads to many moulding problems. In order to avoid these problems the part is analyzed in the mould flow software and the designing process are optimized by varying some of the process parameters.

To perform effective analysis by the professional software Mould flow Plastic Insight, the number of input data has to be produced correctly to get best output result.

Mould flow Plastic Insight (MPI) software which is an integrated suite of analysis tools that utilize CAD files and apply advanced Finite Element Analysis (FEA) techniques to quickly and easily enable a virtual "what if" design environment before initiating mould construction. MPI provides in-depth part/mould design and process parameter optimization.

\subsection{Study of the Component and Material}

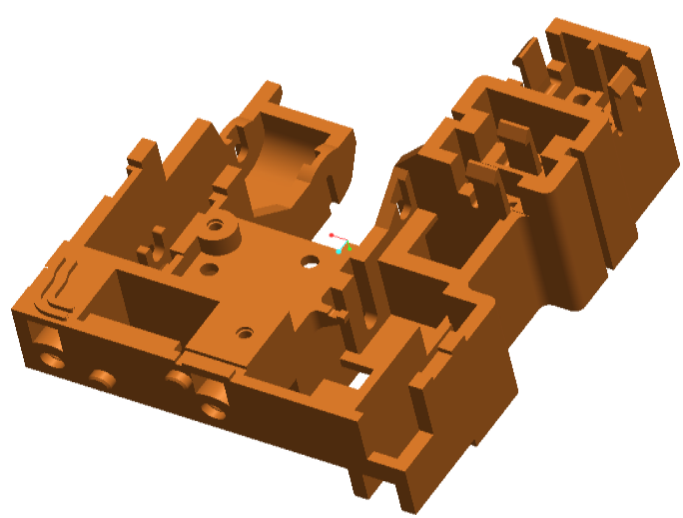

Fig. 1 3D Model of the Component

The component is a Basetta tu base component used as the outside cover in electrical assembly.

The component has to serve for the inserting of many sockets in it. This must have stability in working. Acrylonitrile Butadiene Styrene with MFR $=50 \mathrm{~g} / 10 \mathrm{~min}$. and $0.5 \%$ shrinkage materials is used for the production of this component, which is manufactured by UMG ABS LTD with trade name UMG ABS GSM is used for investigation.

\subsection{Best Gate Location}

The gate location result rates each place on the model for its suitability for an injection location. The most suitable areas are rated as best and the least suitable areas of the model are rated as the worst. If there are no injection locations on the model, the gate locator will determine the best place for the single gate given for selected material.

The gate location represents the position where polymer is injected. In order to mould the best part possible, here we have to decide the optimum injection location for our part. The optimum injection location creates uniform flow. The injection location represents the best possible position where the polymer has to be injected in order to get the components of an acceptable quality level and it should not cause any deflection to the mould.

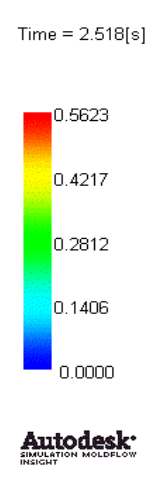

\subsection{Fill Time}

Fill analysis predicts the thermoplastic polymer flow inside the mould in the filling phase. A Fill analysis calculates a flow front that grows through the part incrementally from the injection location. The analysis continues until the velocity/pressure switch-over point has been reached. Fill time is the total time taken by the melt to fill the impression. Fig.3 represents the time taken to fill different sections of the component, which are highlighted in different colors. The time taken to fill the impression is 0.749 seconds. The part is completely filled, so no possibility of short shot.

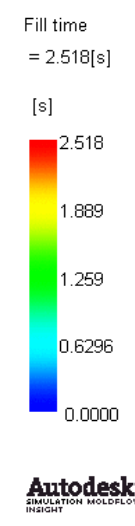

\subsection{Pressure of Fill}

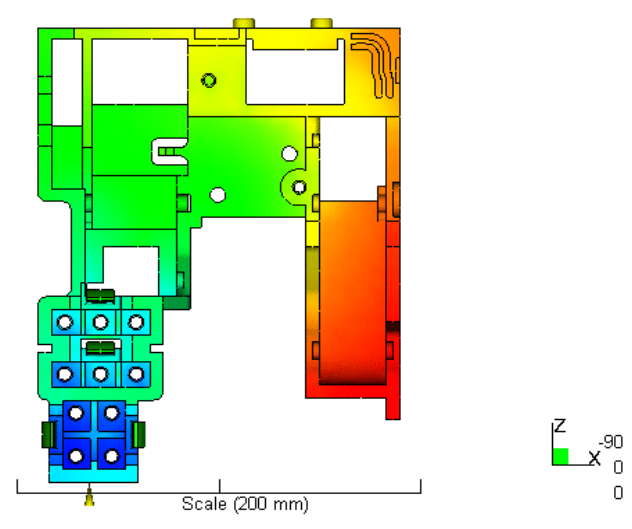

Fig. 3 Fill time

The color at each place on the model represents the drop in pressure from the injection location to that place on the model, 
at the moment that place was filled. The pressure drop result uses a range of colors to indicate the region of highestpressure drop (colored red) through to the region of lowest pressure drop (colored blue). As a part fills with polymer, each point within the part will have a characteristic pressure curve. The pressure drop is one factor used to determine the confidence of fill result. If the pressure drop is greater than $80 \%$ of the current injection pressure setting, then it causes an incomplete filling of mould impression.

This analysis gives the maximum pressure required to fill the impressions. From this we can interpret that the maximum injection pressure required to fill the impressions is $31.49 \mathrm{MPa}$ as shown in Fig. 4 and 5 this result helps in selecting the injection moulding machine.
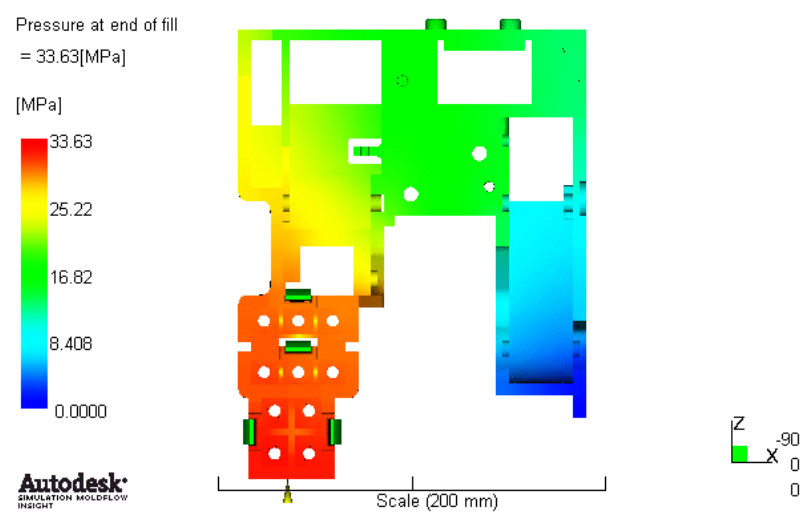

Fig. 4 Pressure of Fill

\subsubsection{Pressure at Injection Locations}

If the fill pressure is close to the pressure/clamp ceiling for the machine, then the Switch-over (packing) pressure should be less than the fill pressure to prevent the mould from flashing. If the fill pressure is substantially less than the pressure ceiling for the machine, it may be possible to use a packing pressure which is greater than the fill pressure, to ensure a product with a good surface finish while not exceeding clamp force limits".

The Fig. 5 shows the plot of variation of pressure during the moulding process.

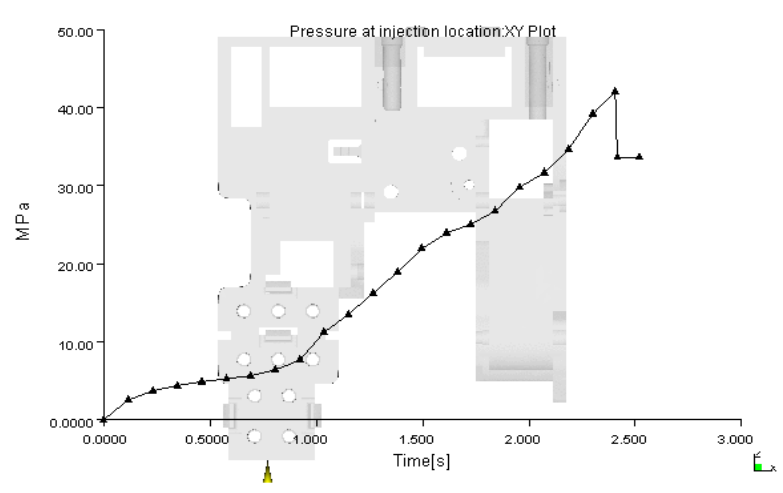

Fig. 5 Pressure at Injection Location

\subsection{Temperature of Flow Front}

The colors represent the material temperature at each point as that point was filled. The result shows the changes in the temperature of flow front during filling. Flow front temperature uses a range of colors to indicate the region of lowest temperature (Colored blue) through to the region of highest temperature (colored red). If the flow front temperature is too low in a thin area of the part, hesitation or short shot may occur. In areas where the flow front temperature is too high, material degradation and surface defects may occur. Make sure that the flow front temperature is always within the recommended temperature range for the polymer we are using.

Fig. 6 shows how the melt temperature changes in various sections of the impressions. From this result we can interpret the difference in temperature inside the moulding. But in this case the temperature is uniform though out.

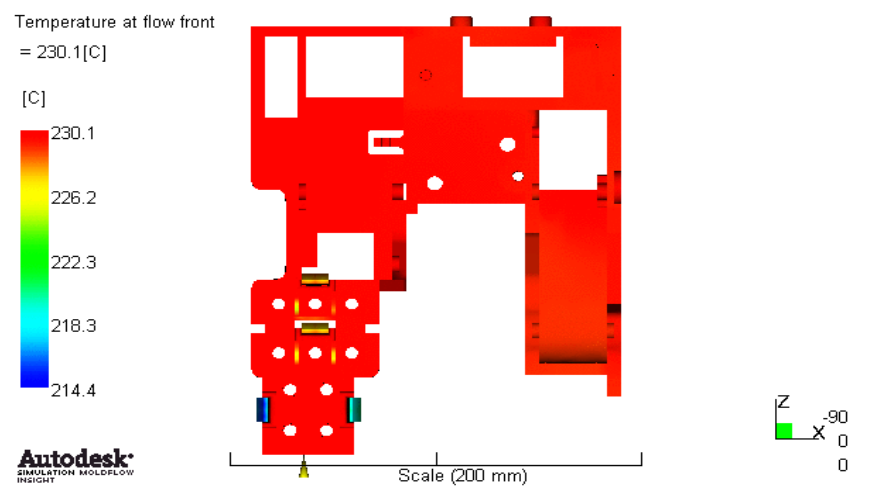

Fig. 6 Temperature at flow front

\subsection{Weld Lines}

This result indicates the presence and location of weld and meld lines in the filled part model. These are the places where two flow fronts have converged. The pressures drop of the weld and meld lines may indicate weakness or blemish. Weld 
line and meld lines on plastic part can cause the structural problems and be visually unacceptable (a line, notch and/or color change can appear). Therefore weld and meld lines should be avoided if possible. Avoid weld lines in areas which need strength or which need to appear smooth, by changing the polymer injection location or altering the wall thickness to set up a different fill time. In different fill time, flow fronts may meet at different location and therefore the weld/meld lines will move.
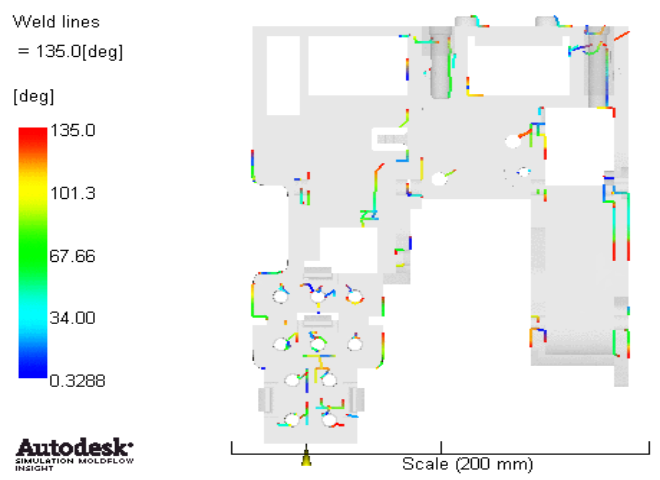

Fig. 7 Weld lines

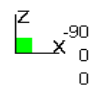

\subsection{Air Traps}

The air trap results shows the regions where the melt stops at convergence of at least two flow fronts or at the last point of fill, where a bubble of air becomes trapped. Air traps can occur when the Converging flow fronts surround and trap a bubble of air. This normally happens where there are unbalanced flow paths. Air traps can cause incomplete filling and pressurization phases, and will often cause a surface blemish in the final part. Air trapped in pockets may compress, heat up and cause burn marks. This analysis interprets the possible air trap locations. For this component the air trap location found is at the top and at the bottom, which is shown the Fig. 8

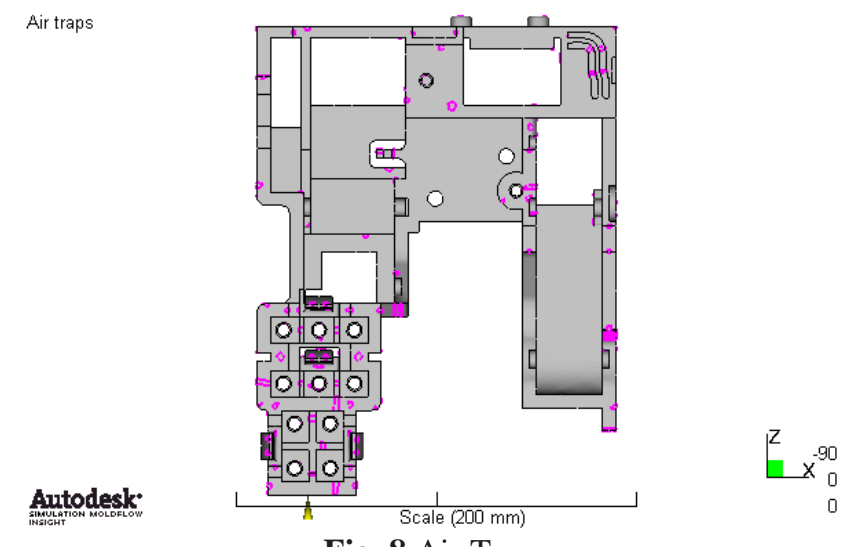

Fig. 8 Air Traps

In order to avoid air traps in the mouldings, proper venting is incorporated in the mould, during the manufacturing stage.

\section{RESULTS}

- Best location of the gate obtained from the analysis which we have selected.

- The fill time observed is $2.518 \mathrm{sec}$, which is helpfull in machine parameter setting.

- Flow lines effects in mould during filling were observed.

- The temperature near the weld line is nearly same as melt temperature, which results weld lines to fuse.

- Most of the air traps are located at the parting surface and bosses, which can be removed by providing suitable air vents in the mould.

\section{CONCLUSIONS}

In the study, mould flow analysis is done for the basetta tu base component to investigate the filling characteristics. The best gate location was obtained in this work, which ensures the product can be filled completely. The possibility of flow lines observation is important for injection mould filling investigation. It helps to understand and solve some problems with mould cavity filling and to obtain part of high quality. One of the possible solutions can be the gate correction or, if it is possible, adding a new injection point.

\section{REFERENCES}

[1] P. Kennedy, Flow Analysis of Injection Moulds, Hanser- Gardner, 1995.

[2] Moldflow. "Simulation Fundamentals Theory and Concepts for MPI 6.0". Mold flow Corporation, Massachusetts. (2006).

[3] W.G. Ryim, Y.I. Kim, S.K. Chang, "A systema-tic optimization of gate location and processing conditions in injection molding", J. Appl. Mech. Trans. ASME 227 (1997) 111-120.

[4] Smorawi ski, Injection moulding technology, WNT, 